\title{
Casting a Wider Net: Engaging Community Health Worker Clients and Their Families in Cancer Prevention
}

\author{
Lee Anne Roman, PhD; Ruth Enid Zambrana, PhD; Sabrina Ford, PhD; \\ Cristian Meghea, PhD; Karen Patricia Williams, PhD
}

\begin{abstract}
Suggested citation for this article: Roman LA, Zambrana RE, Ford S, Meghea C, Williams KP. Casting a Wider Net: Engaging Community Health Worker Clients and Their Families in Cancer Prevention. Prev Chronic Dis 2016;13:160114. DOI: http:// dx.doi.org/10.5888/pcd13.160114.
\end{abstract}

\section{PEER REVIEWED}

\section{Abstract}

Engaging family members in an intervention to prevent breast and cervical cancer can be a way to reach underserved women; however, little is known about whether family member recruitment reaches at-risk women. This study reports the kin relationship and risk characteristics of family members who chose to participate in the Kin Keeper ${ }^{\mathrm{SM}}$ cancer prevention intervention, delivered by community health workers (CHWs) via existing community programs. African American, Latina, and Arab family members reported risk factors for inadequate screening, including comorbid health conditions and inadequate breast or cervical cancer literacy. CHW programs can be leveraged to reach underserved families with cancer preventive interventions.

\section{Objectives}

Health-seeking behavior typically occurs in the context of close family relationships outside of clinical and public health settings (1). The Kin Keeper cancer prevention intervention delivers breast and cervical cancer education to underserved women and their family members (2). The program is not stand-alone; the 2-session intervention piggy-backs on existing community health worker (CHW) programs. However, little is known about family member recruitment and whether family networks are a viable approach for reaching at-risk, underserved women (3). This article describes the risk characteristics of family members engaged in the Kin Keeper trial for 3 racial/ethnic groups.

\section{Methods}

An exploratory analysis was conducted using baseline data from the Kin Keeper randomized trial of a population of African American, Latina, and Arab women and their family members (2). The study was conducted in Detroit and Dearborn, Michigan, and delivered through existing CHW programs (eg, a diabetes program) from June 2010 to February 2015. After being trained, CHWs engaged clients of the program, who in turn invited family members to participate in the intervention in their home. At enrollment, participants completed a questionnaire that inquired about sociodemographic characteristics, health status, health care, health literacy, and screening behaviors related to breast and cervical cancer. Cancer literacy was measured with the Breast Cancer Literacy Assessment Tool (4), a 35-item instrument that assesses respondents' level of knowledge about breast cancer under these these domains: awareness, knowledge and screening, and prevention and control; cervical cancer literacy was assessed with the Cervical Cancer Literacy Assessment Tool (5), a 24-item instrument that assesses the same domains. Adequate cancer literacy was defined as a score of $75 \%$ or higher. Appropriately timed screening was defined as 1) clinical breast examination and mammogram (for women aged $\geq 40 \mathrm{y}$ ) in the previous 12 months; and 2) cervical screening in the previous 3 years. Definitions were based on 2007 recommendations of the American Cancer Society (6) and the 2002 US Preventive Services Task Force (USPSTF) for mammography (7) at the time of study design and are consistent with the Affordable Care Act stipulating coverage for mammography based on the 2002 USPSTF recommendations (8). Exposure to cancer media was defined as seeing, reading, or hearing information about breast or cervical cancer prevention.

Bivariate analyses were used to explore differences between the CHW clients and their family members. Significance was set at $P$ $<.05$. The study was approved by the Michigan State University institutional review board. 


\section{Results}

Overall, 58\% of family members were sisters of the CHW program participants, and more than half were sisters in each of the racial/ethnic groups (Table). Other family participants were mothers $(15 \%)$, daughters $(12 \%)$, and aunts $(11 \%)$. Most family members were aged 40 or older, less than half had any type of employment, 31\% had less than a high school education, 23\% reported an annual family income of less than $\$ 10,000$, and $28 \%$ lacked public or private health insurance. Almost a quarter (24\%) of family participants reported hypertension, 16\% reported diabetes, and one-quarter reported tobacco use. Most family members reported little exposure to cancer information from media, and $50 \%$ or more had no doctor recommendation for mammography or a Pap test. Most family members had inadequate breast (55\%) or cervical $(64 \%)$ cancer literacy. Only $62 \%$ had a mammogram in the previous 12 months, and $72 \%$ had a Pap test in the previous 3 years.

Compared with the CHW program's clients, family members were less likely to have no health insurance ( $28 \%$ vs $46 \%)$, were less likely to have diabetes (16\% vs $32 \%$ ), and have less difficulty accessing a health care provider ( $8 \%$ vs $15 \%)$; however, they were also less likely than CHW clients to have had a Pap test in the past 3 years (72\% vs 84\%). Among African American women, there were no differences in demographic, health, or health care access characteristics or in cancer screening and literacy between the family participants and the $\mathrm{CHW}$ clients. This was also true for Latinas, with one exception: family participants were more likely to be single or never married than CHW clients (24\% vs $5 \%$ ). Among Arab women, family participants were less likely to have diabetes (16\% vs $47 \%$ ) and more likely to have their doctor not recommend a clinical breast exam in the previous year $(67 \%$ vs $42 \%)$ or a Pap test $(60 \%$ vs $43 \%)$ than were $\mathrm{CHW}$ clients.

\section{Discussion}

CHW programs that focus on chronic illness, wellness, or other issues and that enroll underserved African American, Latina, or Arab women were successful in engaging their clients recruit family members for a preventive intervention. Most $\mathrm{CHW}$ clients invited their sisters, and most women were at midlife, an age when it is especially important to intervene to prevent cancer later in life (9). Family members had risk factors for inadequate screening, including financial stressors, comorbid health conditions, and lack of health insurance (10). Most family members and CHW clients had inadequate breast and cervical cancer literacy and low exposure to cancer media. Although family members were more likely to be insured, cancer screening rates among family members were similar to (breast) or lower than (cervical) rates for clients. Therefore,
CHW clients could be important health advocates for other family members. Although the CHW clients were more likely to be uninsured, this finding may be a function of how community-based $\mathrm{CHW}$ programs engage uninsured women. Family members were less likely than CHW clients to have diabetes; however, some clients were invited through a diabetes program. A limitation of the study is that characteristics and screening participation data were self-reported.

To address persistent cancer inequalities, there are calls for increased attention to multilevel factors, such as family context, to improve cancer care and outcomes (11). When family members participate together in an intervention, it allows for shared understanding with the potential that family members will reinforce preventive health behavior for each other. CHWs that serve individual clients can be an important bridge to families (12), and community programs can be leveraged to reach underserved, at-risk women within the broader family unit. To deliver family-focused services, partnerships across public health programs, integration of cancer literacy and screening education, and cross-training of CHWs are needed.

\section{Acknowledgments}

This work was supported by the National Institutes of Health National Institute for Nursing Research (1R01011323). We acknowledge the work of Murlisa Lockett, MA, Community Health Worker Supervisor, for her contributions to this article.

\section{Author Information}

Corresponding Author: Karen Patricia Williams, PhD, Nursing Distinguished Professor of Women's Health, College of Nursing, The Ohio State University, 362 Newton Hall, 1585 Neil Ave, Columbus, OH 43210. Telephone: 614-292-1523. Email: Williams.5963@osu.edu.

Author Affiliations: Lee Anne Roman, Sabrina Ford, Cristian Meghea, Michigan State University, East Lansing, Michigan; Ruth Enid Zambrana, University of Maryland, College Park, Maryland.

\section{References}

1. LaGuardia JG. The influence of the social environment on health behavior. In: Weinstein $\mathrm{N}$, editor. Human motivation and interpersonal relationships: theory, research, and applications. New York (NY): Dordrecht Heidelberg, Springer; 2014.

\footnotetext{
The opinions expressed by authors contributing to this journal do not necessarily reflect the opinions of the U.S. Department of Health and Human Services, the Public Health Service, the Centers for Disease Control and Prevention, or the authors' affiliated institutions.
} 
2. Williams KP, Roman L, Meghea CI, Penner L, Hammad A, Gardiner J. Kin KeeperSM: design and baseline characteristics of a community-based randomized controlled trial promoting cancer screening in Black, Latina, and Arab women. Contemp Clin Trials 2013;34(2):312-9.

3. Livaudais JC, Coronado GD, Espinoza N, Islas I, Ibarra G, Thompson B. Educating Hispanic women about breast cancer prevention: evaluation of a home-based promotora-led intervention. J Womens Health (Larchmt) 2010; 19(11):2049-56.

4. Williams KP, Templin TN, Hines RD. Answering the call: a tool that measures functional breast cancer literacy. J Health Commun 2013;18(11):1310-25.

5. Williams KP, Templin TN. Bringing the real world to psychometric evaluation of cervical cancer literacy assessments with Black, Latina, and Arab women in real-world settings. J Cancer Educ 2013;28(4):738-43.

6. Saslow D, Boetes C, Burke W, Harms S, Leach MO, Lehman $\mathrm{CD}$, et al.;American Cancer Society Breast Cancer Advisory Group. American Cancer Society guidelines for breast screening with MRI as an adjunct to mammography. CA Cancer J Clin 2007;57(2):75-89. Erratum in CA Cancer J Clin 2007;57:185

7. Humphrey LL, Helfand M, Chank BKS, Woolf SH. Breast cancer screening: a summary of the evidence for the US Preventive Services Task Force. Ann Intern Med 2002; 137(Part 1):344-6.

8. The Patient Protection and Affordable Care Act of 2010. Public Law. 2010;111-48.

9. Holman DM, Grossman M, Henley SJ, Peipins LA, Tison L, White MC. Opportunities for cancer prevention during midlife: highlights from a meeting of experts. Am J Prev Med 2014; 46(3,Suppl 1):S73-80.

10. Gerend MA, Pai M. Social determinants of Black-White disparities in breast cancer mortality: a review. Cancer Epidemiol Biomarkers Prev 2008;17(11):2913-23.

11. Taplin SH, Anhang Price R, Edwards HM, Foster MK, Breslau ES, Chollette V, et al. Introduction: Understanding and influencing multilevel factors across the cancer care continuum. J Natl Cancer Inst Monogr 2012;2012(44):2-10.

12. Islam N, Nadkarni SK, Zahn D, Skillman M, Kwon SC, TrinhShevrin C. Integrating community health workers within Patient Protection and Affordable Care Act implementation. J Public Health Manag Pract 2015;21(1):42-50.

The opinions expressed by authors contributing to this journal do not necessarily reflect the opinions of the U.S. Department of Health and Human Services, the Public Health Service, the Centers for Disease Control and Prevention, or the authors' affiliated institutions. 


\section{Table}

Table. Bivariate Comparisons of CHW Program Participants to Recruited Family Member Participants, Overall $(\mathrm{N}=516)$ and by Racial/Ethnic Group ${ }^{\mathrm{a}}$

\begin{tabular}{|c|c|c|c|c|c|c|c|c|}
\hline \multirow[b]{2}{*}{ Characteristic } & \multicolumn{2}{|c|}{ All } & \multicolumn{2}{|c|}{ African American } & \multicolumn{2}{|c|}{ Latina } & \multicolumn{2}{|c|}{ Arab } \\
\hline & $\begin{array}{c}\text { CHW } \\
\text { Participants } \\
(\mathrm{N}=171)\end{array}$ & $\begin{array}{c}\text { Family } \\
\text { Participants } \\
(n=343)\end{array}$ & $\begin{array}{c}\text { CHW } \\
\text { Participants } \\
(n=72)\end{array}$ & $\begin{array}{c}\text { Family } \\
\text { Participants } \\
(n=144)\end{array}$ & $\begin{array}{c}\text { CHW } \\
\text { Participants } \\
(n=22)\end{array}$ & $\begin{array}{c}\text { Family } \\
\text { Participants } \\
(n=43)\end{array}$ & $\begin{array}{c}\text { CHW } \\
\text { Participants } \\
(n=78)\end{array}$ & $\begin{array}{c}\text { Family } \\
\text { Participants } \\
(\mathrm{n}=157)\end{array}$ \\
\hline \multicolumn{9}{|c|}{ Demographic } \\
\hline \multicolumn{9}{|l|}{ The family member I invited is my ... } \\
\hline Daughter & 11.6 & NA & 11.2 & NA & 7.69 & NA & 13.0 & NA \\
\hline Mother & 15.0 & NA & 9.7 & $\mathrm{NA}$ & 15.38 & $\mathrm{NA}$ & 19.5 & $N A$ \\
\hline Granddaughter & 2.4 & NA & 3.7 & NA & 0 & NA & 0.6 & $\mathrm{NA}$ \\
\hline Sister & 58.4 & NA & 53.0 & NA & 66.67 & NA & 61.0 & NA \\
\hline Aunt & 11.3 & NA & 14.2 & $\mathrm{NA}$ & 5.13 & $\mathrm{NA}$ & 5.2 & $\mathrm{NA}$ \\
\hline Mean age, $y$ & 43 & 45 & 42 & 45 & 41 & 43 & 45 & 46 \\
\hline$<40$ & 33.7 & 33.0 & 43.1 & 35.9 & 43.86 & 39.5 & 22.4 & 28.5 \\
\hline $40-49$ & 37.3 & 32.7 & 29.2 & 28.9 & 42.86 & 32.6 & 43.4 & 36.4 \\
\hline$\geq 50$ & 29.0 & 34.2 & 27.8 & 35.2 & 14.29 & 27.9 & 34.2 & 35.1 \\
\hline Education level <high school & 27.7 & 31.3 & 5.8 & 11.5 & 61.9 & 69.0 & 38.2 & 39.0 \\
\hline Single/never married & 25.0 & 29.7 & 52.9 & 50.7 & $4.55^{\mathrm{c}}$ & 24.4 & 5.3 & 10.9 \\
\hline Annual family income $<\$ 10,000$ & 26.9 & 23.0 & 22.2 & 20.1 & 59.09 & 39.5 & 22.1 & 21.2 \\
\hline $\begin{array}{l}\text { Work full-time, work part-time, or self- } \\
\text { employed }\end{array}$ & 46.4 & 43.3 & 61.4 & 61.6 & 31.82 & 29.7 & 36.8 & 30.3 \\
\hline No health insurance coverage & $46.1^{c}$ & 28.4 & 29.6 & 16.1 & 77.27 & 53.7 & 52.7 & 33.1 \\
\hline \multicolumn{9}{|c|}{ Health } \\
\hline High blood pressure & 23.4 & 24.5 & 37.5 & 29.2 & 18.18 & 14.0 & 11.7 & 23.1 \\
\hline Diabetes & $31.6^{c}$ & 16.0 & 20.8 & 15.3 & 13.64 & 18.6 & $46.8^{c}$ & 16.0 \\
\hline Depression & 13.4 & 10.2 & 9.7 & 9.7 & 13.64 & 7.0 & 16.9 & 11.5 \\
\hline Tobacco use & 24.1 & 24.8 & 22.2 & 31.4 & $-{ }^{d}$ & 2.3 & 33.3 & 25.2 \\
\hline Average, poor, or very poor health & 28.6 & 26.4 & 21.1 & 27.3 & 36.37 & 27.9 & 28.4 & 30.1 \\
\hline \multicolumn{9}{|c|}{ Health Care } \\
\hline Difficult access to the health provider & $14.7^{c}$ & 8.0 & 12.5 & 6.3 & 27.27 & 16.7 & 13.2 & 7.2 \\
\hline Needed to reschedule appointments & 41.8 & 35.5 & 44.1 & 29.8 & 40.91 & 57.6 & 39.7 & 35.2 \\
\hline $\begin{array}{l}\text { No doctor recommended clinical breast } \\
\text { exam past year }\end{array}$ & $55.4^{c}$ & 65.4 & 64.3 & 63.4 & 72.73 & 65.8 & $42.1^{c}$ & 67.1 \\
\hline $\begin{array}{l}\text { No doctor recommended mammography } \\
\text { past year (age } \geq 40)\end{array}$ & 54.5 & 49.8 & 61.0 & 48.9 & 66.67 & 46.2 & 47.5 & 51.4 \\
\hline $\begin{array}{l}\text { No doctor recommended PAP test past } 3 \\
\text { years }\end{array}$ & 56.8 & 60.2 & 70.8 & 60.1 & 59.09 & 60.5 & $42.7^{c}$ & 60.3 \\
\hline Clinical breast exam in the past 12 months & 63.1 & 59.8 & 63.4 & 60.1 & 54.55 & 44.2 & 65.3 & 63.8 \\
\hline
\end{tabular}

Abbreviations: CHW, community health worker; NA, not applicable; PAP, Papilloma.

a Values are percentages unless otherwise indicated.

${ }^{\mathrm{b}}$ Only the recruited family members (ie, not the initial $\mathrm{CHW}$ program participant) responded to this question.

${ }^{\mathrm{c}} P<.05$.

${ }^{\mathrm{d}}$ Number for Latinas who used tobacco was too small to calculate.

(continued on next page)

The opinions expressed by authors contributing to this journal do not necessarily reflect the opinions of the U.S. Department of Health and Human Services, the Public Health Service, the Centers for Disease Control and Prevention, or the authors' affiliated institutions. 
(continued)

Table. Bivariate Comparisons of CHW Program Participants to Recruited Family Member Participants, Overall $(\mathrm{N}=516)$ and by Racial/Ethnic Group ${ }^{\mathrm{a}}$

\begin{tabular}{|c|c|c|c|c|c|c|c|c|}
\hline \multirow[b]{2}{*}{ Characteristic } & \multicolumn{2}{|c|}{ All } & \multicolumn{2}{|c|}{ African American } & \multicolumn{2}{|c|}{ Latina } & \multicolumn{2}{|c|}{ Arab } \\
\hline & $\begin{array}{c}\text { CHW } \\
\text { Participants } \\
(\mathrm{N}=171)\end{array}$ & $\begin{array}{c}\text { Family } \\
\text { Participants } \\
(n=343)\end{array}$ & $\begin{array}{c}\text { CHW } \\
\text { Participants } \\
(n=72)\end{array}$ & $\begin{array}{c}\text { Family } \\
\text { Participants } \\
(n=144)\end{array}$ & $\begin{array}{c}\text { CHW } \\
\text { Participants } \\
(n=22)\end{array}$ & $\begin{array}{c}\text { Family } \\
\text { Participants } \\
(n=43)\end{array}$ & $\begin{array}{c}\text { CHW } \\
\text { Participants } \\
(n=78)\end{array}$ & $\begin{array}{c}\text { Family } \\
\text { Participants } \\
(n=157)\end{array}$ \\
\hline $\begin{array}{l}\text { Mammography in the past } 12 \text { months (age } \\
\geq 40 \text { ) }\end{array}$ & 63.4 & 62.2 & 70.0 & 59.3 & 33.33 & 57.7 & 62.7 & 68.2 \\
\hline PAP test in the past 3 years & $84.0^{\mathrm{c}}$ & 71.6 & 90.3 & 79.9 & 90.91 & 55.8 & 76.0 & 68.6 \\
\hline \multicolumn{9}{|c|}{ Health Literacy } \\
\hline Inadequate breast cancer literacy & 52.0 & 54.8 & 54.2 & 50.7 & 68.18 & 69.8 & 45.4 & 54.5 \\
\hline Inadequate cervical cancer literacy & 60.8 & 64.4 & 58.3 & 60.4 & 63.64 & 74.4 & 62.3 & 65.4 \\
\hline No knowledge of cancer history in the family & 24.7 & 25.7 & 27.8 & 32.6 & 22.73 & 32.6 & 22.4 & 17.7 \\
\hline $\begin{array}{l}\text { No or low recent exposure to breast cancer } \\
\text { media }\end{array}$ & 53.3 & 45.6 & 44.9 & 32.6 & 81.82 & 61.9 & 52.6 & 52.6 \\
\hline $\begin{array}{l}\text { No or low recent exposure to cervical cancer } \\
\text { media }\end{array}$ & 65.7 & 60.5 & 56.3 & 52.2 & 95.45 & 78.0 & 65.8 & 63.0 \\
\hline
\end{tabular}

Abbreviations: CHW, community health worker; NA, not applicable; PAP, Papilloma.

${ }^{a}$ Values are percentages unless otherwise indicated.

${ }^{\mathrm{b}}$ Only the recruited family members (ie, not the initial $\mathrm{CHW}$ program participant) responded to this question.

${ }^{\mathrm{c}} P<.05$.

${ }^{d}$ Number for Latinas who used tobacco was too small to calculate. 